\title{
Thermophilic endospores associated with migrated thermogenic hydrocarbons in deep Gulf of Mexico marine sediments
}

\author{
Anirban Chakraborty ${ }^{1} \cdot$ Emily Ellefson ${ }^{1} \cdot$ Carmen $_{\mathrm{Li}^{1}} \cdot$ Daniel Gittins ${ }^{1} \cdot$ James M. Brooks $^{2} \cdot$ Bernie B. Bernard $^{2} \cdot$ \\ Casey R. J. Hubert ${ }^{1}$
}

Received: 9 December 2017 / Revised: 16 February 2018 / Accepted: 12 March 2018 / Published online: 29 March 2018

(c) The Author(s) 2018. This article is published with open access

\begin{abstract}
Dormant endospores of thermophilic bacteria (thermospores) can be detected in cold marine sediments following hightemperature incubation. Thermospores in the cold seabed may be explained by a dispersal history originating in deep biosphere oil reservoir habitats where upward migration of petroleum fluids at hydrocarbon seeps transports viable cells into the overlying ocean. We assessed this deep-to-shallow dispersal hypothesis through geochemical and microbiological analyses of 111 marine sediments from the deep water Eastern Gulf of Mexico. GC-MS and fluorescence confirmed the unambiguous presence of thermogenic hydrocarbons in 71 of these locations, indicating seepage from deeply sourced petroleum in the subsurface. Heating each sediment to $50{ }^{\circ} \mathrm{C}$ followed by $16 \mathrm{~S}$ rRNA gene sequencing revealed several thermospores with a cosmopolitan distribution throughout the study area, as well as thermospores that were more geographically restricted. Among the thermospores having a more limited distribution, 12 OTUs from eight different lineages were repeatedly detected in sediments containing thermogenic hydrocarbons. A subset of these were significantly correlated with hydrocarbons $(p<0.05)$ and most closely related to Clostridiales previously detected in oil reservoirs from around the world. This provides evidence of bacteria in the ocean being dispersed out of oil reservoirs, and suggests that specific thermospores may be used as model organisms for studying warm-to-cold transmigration in the deep sea.
\end{abstract}

\section{Introduction}

A large proportion of Earth's biomass, estimated to be close to $10^{30}$ cells, is found in dark warm subsurface habitats where biodiversity is comprised exclusively of microorganisms [1-5]. Recent research has shown active populations of anaerobic microbes, many of which are thermophiles, in deeply buried anoxic sediments, oil reservoirs [6, 7], permeable ocean crust [8], and around hydrothermal vents at mid-ocean ridges [9]. Geological features enabling seabed fluid flow from warm to cold

Electronic supplementary material The online version of this article (https://doi.org/10.1038/s41396-018-0108-y) contains supplementary material, which is available to authorized users.

Anirban Chakraborty

anirban.chakraborty@ucalgary.ca

1 Department of Biological Sciences, University of Calgary, Calgary, AB, Canada

2 TDI Brooks International, College Station, TX, USA environments, such as hydrocarbon seeps and mid-ocean ridge-associated vents or seamounts, physically connect subsurface ecosystems to the overlying oceans [10, 11]. The transport of cells from subsurface habitats up into the overlying ocean may contribute to marine microbial biodiversity [12, 13], including the well documented 'rare biosphere' [14-17]. This marine microbial seed bank is largely comprised of dormant microorganisms [18], including inactive endospores of thermophilic bacteria, i.e., thermospores [19-21].

Microbial biodiversity surveys generally do not detect bacterial endospores, most likely due to endospore resistance to physical or chemical lysis steps employed during community DNA extraction from environmental samples [22, 23]. High temperature, anoxic incubations have therefore been employed to study thermospores [24] and have revealed annual influx rates of $10^{7}$ and $10^{8}$ spores per square meter in the cold seabed sediments of Aarhus Bay and Svalbard, respectively [19, 25]. These thermospores include close relatives of anaerobic Clostridia that inhabit hot petroleum reservoirs [26-28]. A large-scale investigation of thermospore biogeography from 81 marine sediments 
showed a non-random distribution pattern globally and identified ocean circulation as a major contributor in controlling thermospore dispersal from their source habitats [20]. Taken together, high local influx rates, phylogenetic similarity with oil-reservoir-derived microorganisms, and non-random distribution suggest a dispersal history of thermospores influenced by vectors facilitating passive transport from petroleum-bearing subsurface strata characterized by sufficient magnitude and fluid flow to maintain a steady supply of endospores [29]. Seabed hydrocarbon seeps, where gas and oil in leaky subsurface reservoirs are expelled up to the seafloor, offer an example of an active geofluid-flow system linking the deep and shallow biospheres [11] that could satisfy the above criteria for thermospore dispersal.

Marine sediments in and around hydrocarbon seeps are generally replete with petroleum-associated compounds and provide access to plethora of organic growth substrates for microbial communities compared to otherwise oligotrophic deep sea sediments [30]. Hydrocarbon seeps thus host microbiomes which are locally selected and are largely distinct from surrounding seafloor ecosystems [31]. The Gulf of Mexico (GoM) basin is well known for widespread natural seepage of petroleum-derived hydrocarbons sourced from deeply buried oil and gas reservoirs, with an estimated annual oil discharge rate of more than $30,000 \mathrm{~m}^{3}$ [32-34]. Cold-temperature-adapted microbial communities at GoM seeps have thus been studied in great detail in relation to the impact of hydrocarbons on community diversity [35, 36], sulfate reduction [37], and hydrocarbon biodegradation [38] whereas thermospores have received far less attention. Given that endospore-forming anaerobic Clostridia inhabit hot petroleum reservoirs such as those in the GoM basin, it is conceivable that these endospores could migrate upward with naturally seeping petroleum fluids and eventually get deposited in the overlying surface sediments [29]. Consistent with this, recent investigations of six reservoirs in the adjacent (onshore) Gulf coastal plain revealed a predominance of Clostridiales [39] adding to the number of studies indicating that thermophilic Firmicutes are prevalent in high-temperature oil fields [40].

We therefore addressed the following questions in this study; are thermospores present in petroleum-rich surface sediments of the Gulf of Mexico? Can regional-scale biogeography of thermospores reveal distinguishable distributions in marine sediments with geochemical signatures of migrated thermogenic hydrocarbons? Can hydrocarbon seep-driven endemism of thermospores be observed, i.e., do anomalies for taxa and hydrocarbons co-exist? To address the above questions, we analyzed the phylogeny and distribution of thermospores in 111 marine sediments from the Eastern Gulf of Mexico (EGoM) while simultaneously assessing thermogenic hydrocarbon content by measuring a suite of geochemical parameters. Previous investigations of thermospores predicted but could not directly demonstrate deep subsurface origins of these organisms. Our study addresses this by investigating thermospores in marine sediments with direct evidence of migrated hydrocarbons.

\section{Materials and methods}

\section{Sampling of marine sediments}

Marine surface sediments $(0-20 \mathrm{~cm}$ below seafloor) were collected from 111 locations in the Eastern Gulf of Mexico (Fig. 1; Supplementary Table S1) during January-March, 2011, aboard RV GeoExplorer as part of TDI Brooks International's Surface Geochemical Exploration (SGE) program. Sediments were sampled from a range of water depths, and were distributed within four geologic provinces: the Abyssal Plain $(n=66$; average water depth $=3024 \mathrm{~m})$, the De Soto Valley $(n=19$; average water depth $=2143$ $\mathrm{m})$, the Mississippi Canyon $(n=12$; average water depth $=$ $982 \mathrm{~m}$ ), and the West Florida Shelf ( $n=14$; average water depth $=942 \mathrm{~m}$ ). The overall average water depth was 2390 $\mathrm{m}$ with a large majority $(n=82 / 111)$ being $>2000 \mathrm{~m}$. Pairwise geographic distances between sampling locations ranged from 0.23 to $640 \mathrm{~km}$. Piston cores penetrating 4.5-5.5 $\mathrm{m}$ depth were collected and immediately extruded into $20 \mathrm{~cm}$ sections. Surface sediments for microbiological analyses were sealed in sterile Whirl-Pak bags with minimum air exposure and kept frozen at $-20{ }^{\circ} \mathrm{C}$. Deeper intervals for thermogenic hydrocarbon analyses were also frozen at $-20^{\circ} \mathrm{C}$. For analysis of interstitial light hydrocarbon gases, a portion of the deepest section was placed in $500 \mathrm{ml}$ gas cannisters containing clean, degassed, and sterilized seawater. Cannisters were purged with nitrogen and stored at $-20^{\circ} \mathrm{C}$.

\section{Hydrocarbon characterization}

Hydrocarbon analyses were performed on solvent extracts prepared from three equidistant segments from the bottom half of each piston core, representing a depth range of 2-5.5 $\mathrm{m}$ below seafloor. Frozen sediments were thawed, oven-dried at $40^{\circ} \mathrm{C}$, and $15 \mathrm{~g}$ portions were solvent extracted with hexane using an automated extraction apparatus (Dionex ASE200). Liquid petroleum hydrocarbons were analyzed using (1) total scanning fluorescence (TSF) intensities, a semi-quantitative analytical technique selectively sensitive to aromatic hydrocarbons, and (2) gas chromatography of the same extracts to obtain total concentrations of $\mathrm{C}_{15}+$ hydrocarbons, including determination of the unresolved complex mixture (UCM). A detailed 


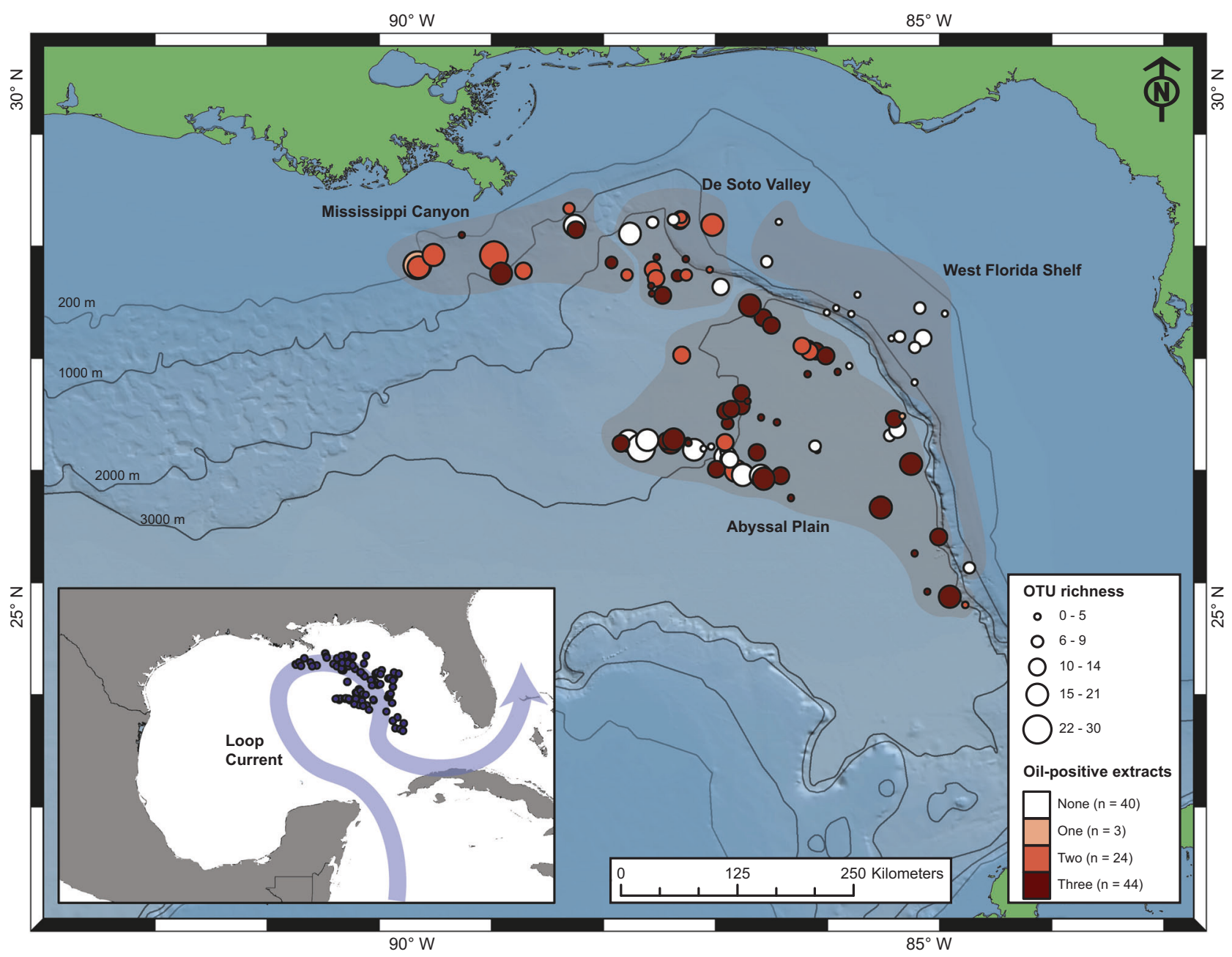

Fig. 1 Map of the Eastern Gulf of Mexico (GoM) showing the 111 sampling locations and bathymetry of the study area. Circle sizes indicate thermospore OTU richness for each location. Color shades of the circles indicate the number of oil-qualified extracts $(n=0,1,2,3)$ in the sediment core for that location. The semi-transparent dark polygons indicate four different geologic provinces within the sampling area. The inset map shows the location and extent of the study area relative to the area of the entire GoM basin as well as the region affected by the Loop Current, the major ocean current in the GoM. Maps were drawn using ArcGIS Desktop 10.4 description of the above geochemical methods has been provided elsewhere [41].

Hydrocarbon parameters are presented as the mean of individual measurements obtained from three extracts per piston core described above. To group locations based on the above measurements, thresholds were set for TSF and UCM. A conventional TSF maximum intensity threshold of 10,000 is often used as an indicator of migrated petroleum in prospective basins around the world [41]; however, this threshold was elevated five-fold (50,000 intensity units) for interpreting the TSF values obtained in this study. This much more stringent TSF threshold was chosen to account for the relatively large input of terrigenous organic matter in the GoM compared to other basins [42]. If an extract or a location gave individual or mean TSF intensities of less than 50,000 and a UCM of lower than $10 \mu \mathrm{g} / \mathrm{g}$ sediment, the extract or the location was disqualified for unambiguous occurrence of thermogenic hydrocarbons. Based on these thresholds, the locations were classified as 'oil-negative' and 'oil-positive', respectively.

\section{Incubation of pasteurized sediment slurries at $50^{\circ} \mathrm{C}$}

Triplicate slurries were prepared from 0 to $20 \mathrm{~cm}$ surface sediment from each of the 111 locations in order to investigate thermospore germination and growth. Non-homogenized, frozen sediments were thawed overnight and three separate aliquots (approximately $10 \mathrm{~g}$ each) were directly added to three separate sterile $50 \mathrm{ml}$ serum bottles inside a walk-in cold room $\left(4^{\circ} \mathrm{C}\right)$. Serum bottles were immediately sealed with sterile black butyl stoppers and the headspace exchanged with $\mathrm{N}_{2}: \mathrm{CO}_{2}$. Sediment aliquots were subsequently diluted in a 1:2 (w/w) ratio with anoxic, artificial seawater medium [43] containing $20 \mathrm{mM}$ sulfate under a 
constant flow of $\mathrm{N}_{2}: \mathrm{CO}_{2}$. To minimize competition for limited substrates between different microbial groups (e.g., sulfate-reducing and fermentative bacteria) the slurries were amended with a combination of six low-molecular-weight organic acids (acetate, butyrate, formate, lactate, propionate, and succinate), each at a final concentration of $5 \mathrm{mM}$. Slurries were pasteurized at $80^{\circ} \mathrm{C}$ for $1 \mathrm{~h}$ to eliminate viable vegetative cells and were incubated at $50^{\circ} \mathrm{C}$ immediately afterwards to promote germination and growth of thermophilic endospores. Initial time-zero samples were taken before pasteurization and slurries were incubated for 2 weeks, with sub-sampling every $2-3$ days. Subsamples (1-2 ml) were removed using $\mathrm{N}_{2}: \mathrm{CO}_{2}$-flushed sterile syringes and immediately centrifuged at $14,000 \times g$ for $10 \mathrm{~min}$. Resulting supernatant and pellet samples were stored separately at $-20{ }^{\circ} \mathrm{C}$ and used for liquid chromatography (see Supplementary Methods) and DNA extractions, respectively.

\section{$16 S$ rRNA gene amplicon sequencing}

Genomic DNA was extracted from subsamples of triplicate sediment slurries after 2 weeks of incubation (14-day), and from the corresponding unheated in situ sediments (0-day). Equal volumes of slurry from each replicate subsample were pooled and the mixed slurry was used for DNA extraction using the PowerLyzer PowerSoil DNA isolation kit (now known as the DNeasy PowerLyzer PowerSoil kit, MO BIO Laboratories, a Qiagen Company, Carlsbad, CA, USA). The v3-4 region of the bacterial 16S rRNA gene was amplified using the primer pair SD-Bact-341-bS17/SDBact-785-aA21 [44] modified with Illumina MiSeq overhang adapters. All PCR reactions were performed in triplicate, pooled, purified, and indexed according to Illumina's $16 \mathrm{~S}$ amplicon library preparation guide (see Supplementary Methods for more details). Indexed amplicons were then pooled in equimolar amounts and sequenced using Illumina's v3 600-cycle (paired-end) reagent kit on a MiSeq benchtop sequencer (Illumina Inc., San Diego, CA, USA). Bacterial diversity in 0-day sediment samples was anticipated to be greater than in 14-day sediment samples, so these samples were loaded onto the MiSeq sequencer at twice the DNA concentration to ensure at least 10,000 and 5000 reads for 0-day and 14-day libraries, respectively, post quality control.

\section{Sequence processing and diversity analyses}

In total, $13,662,481$ paired-end raw reads were processed using the MetaAmp web-based bioinformatics pipeline [45]. After assembly, quality control, de-replication, removal of singletons, and chimeric sequences, 5,119,876 usable single reads were clustered into operational taxonomic units (OTUs) based on a $97 \%$ sequence identity threshold over 350 bases. All libraries were rarefied to 5000 reads in order to eliminate biases arising from variability in library size. Alpha-diversity metrics (observed OTU richness, chao1 richness, Shannon and Simpson diversity indices, and equitability index) were calculated from the rarefied libraries using Mothur version 1.35.1. For beta diversity analyses, the libraries were grouped separately based on before and after incubation (0-day and 14-day). Community similarities were measured using the BrayCurtis and weighted UniFrac indices. All beta diversity analyses were conducted using the phyloseq $\mathrm{R}$ package [46]. Amplicon sequences generated in this study are available through the NCBI Sequence Read Archive (BioProject accession number PRJNA415828).

\section{Identification of putative thermospore OTUs}

Putative thermospore OTUs were defined as follows. First, OTUs had to be affiliated with the phylum Firmicutes, to which all known endospore-forming bacteria belong [47]. Second, each OTU had to significantly increase in relative abundance in at least one heated sediment incubation; this is based on the assumption that many thermospores will germinate and grow at $50{ }^{\circ} \mathrm{C}$ after surviving the initial pasteurization. Significant increase of an OTU was defined as a $0.5 \%$ increase in relative abundance in a 14-day library (i.e., 25 sequences), and validated by performing a twoproportion Z-test between the 0- and 14-day libraries from the same locations. Differences of proportions amounting to $0.5 \%$ relative abundance and higher corresponded to $p$-values of 0.0001 and lower, and were considered significant. Subsequently, each thermospore OTU was evaluated in all other sediments and considered present if its relative abundance was at least $0.1 \%$ (5 sequences) in 14day rarefied amplicon libraries for other locations. These criteria were applied to avoid biases from cross-sample or carry-over contamination during sequencing on the MiSeq platform [45, 48]. Based on these criteria, a presence-absence matrix for thermospore OTUs was calculated and visualized as bipartite networks showing the OTU connectivity with sampling locations using the igraph $\mathrm{R}$ package [49]. The association of each OTU with the parameters indicative of migrated hydrocarbons (TSF and UCM values) was evaluated using point biserial correlation (R package "wCorr") [50] and the correlation coefficients $\left(r_{\mathrm{pb}-\mathrm{TSF}}\right.$ and $\left.r_{\mathrm{pb}-\mathrm{UCM}}\right)$ were reported for OTUs showing significant correlation.

\section{Phylogeny}

Representative sequences from MetaAmp for thermospore OTUs that significantly increased in relative abundance 
were automatically aligned using the web-based SINA aligner [51] and imported into the ARB-SILVA database SSU Ref NR 128 [52] using the ARB software package [53]. A maximum likelihood (PhyML) tree was calculated using almost full-length 16S rRNA sequences (1400 nt) from closely related reference bacteria or environmental clones based on 1183 alignment positions by using positional variability and termini filters for bacteria. Using the ARB Parsimony tool, the short amplicon sequences were added to this tree applying the 50\% sequence conservation filter and positional variability filters covering the length of the representative sequences for each OTU without changing the overall tree topology. Trees were visualized and annotated using iTOL version 3 [54].

\section{Results}

\section{Migrated hydrocarbons in deep water Gulf of Mexico surface sediments}

The distributions of migrated hydrocarbons and thermophilic endospores were investigated in four geological provinces in the Eastern Gulf of Mexico (Fig. 1). TSF intensities and the mass of the UCM were used as the two major indicators of migrated liquid petroleum, since the 'thermogenicity trend' of these two parameters remains linear over several orders of magnitude $[55,56]$. TSF intensities are generally independent of microbial alteration of hydrocarbon compounds and provide a measure of petroleum-related aromatic hydrocarbon concentrations. The UCM on the other hand represents a suite of biodegraded saturated hydrocarbons that are not easily separated using gas chromatography, resulting in a hump-shaped baseline with numerous smaller peaks representing individual compounds. TSF and UCM values ranged from 1800 to 178,016 intensity units and 2 to $52 \mu \mathrm{g} / \mathrm{g}$ dry sediment, respectively. These two parameters were positively correlated $\left(R^{2}=0.415 ; n=111\right)$ among all locations (Fig. 2). The thermogenic nature of the hydrocarbons was further confirmed through measurement of total $\mathrm{C}_{15+}$ alkanes and the thermogenic/diagenetic (T/D) ratio (see Supplementary Results and Supplementary Figure S1 for more details).

To evaluate thermospore distribution in accordance with the presence of migrated petroleum, thresholds were set for TSF and UCM. Based on these thresholds, 40 and 71 locations were classified as oil-negative and oil-positive, respectively (Fig. 2, Supplementary Table S1). Among the oil-positive locations, 44 had very strong indications, with all 3 sediment extracts from the same piston core being above TSF and UCM thresholds, while 24 had two-out-ofthree qualified extracts, and 3 locations had only one qualified extract (Figs. 1 and 2). The Mississippi Canyon

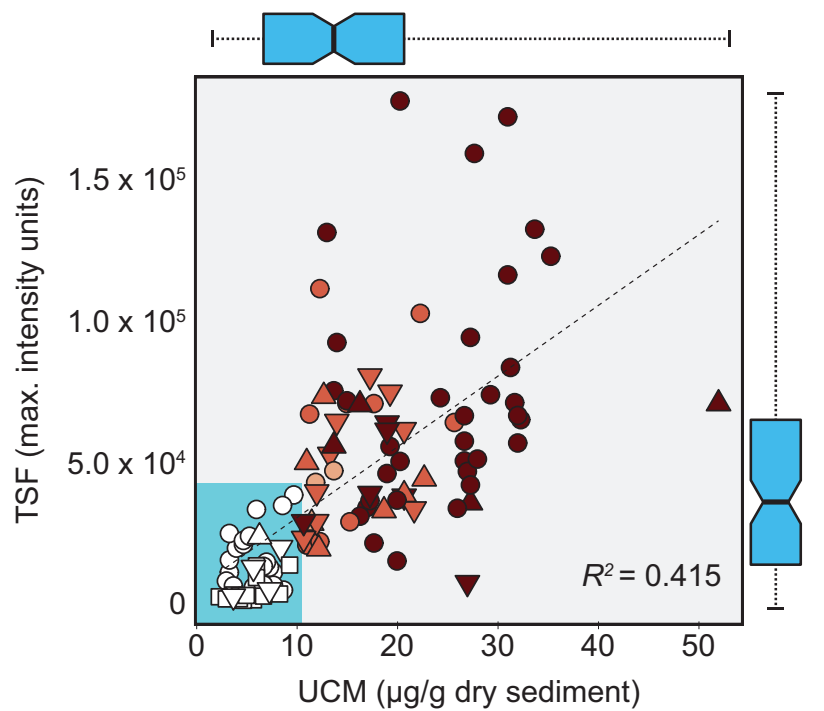

Provinces

Oil-positive extracts
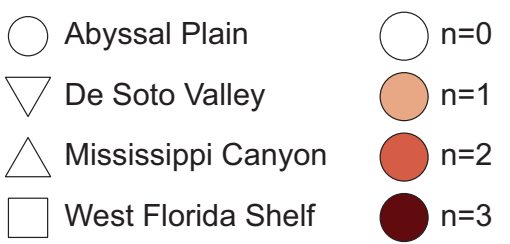

Fig. 2 Scatterplot showing the mean values ( $n=3$ extracts) of two geochemical parameters used for assessing the thermogenic hydrocarbon content in 111 sediment cores. The plot is accompanied by two marginal box-and-whisker plots summarizing the distribution (minimum, lower quartile, median, upper quartile, and maximum) for each of the parameters on the corresponding parallel axes. The dashed line represents the linear regression of the parameters with the corresponding $R^{2}$ value indicated. The cyan-shaded box highlights the UCM and the TSF (maximum intensity) thresholds used by industry for qualifying and/or disqualifying individual sediment extracts for thermogenic hydrocarbon content. Symbol colors indicate the number of qualified extracts $(n=0,1,2$, or 3 out of 3$)$ in each sediment core, according to the thresholds. Symbol shapes indicate the different geologic provinces

province contained the highest percentage of oil-positive samples $(91.7 \% ; n=11 / 12)$, while all 14 samples from West Florida Shelf were oil-negative (Fig. 1). In addition to having low TSF and UCM values, sediments from the 14 relatively shallow West Florida Shelf locations showed very low values for other hydrocarbon parameters while the average concentration of $\mathrm{C}_{15+}$ alkanes was highest $(2.5 \mu \mathrm{g} / \mathrm{g}$ dry sediment) in the Mississippi Canyon province (Supplementary Figure $\mathrm{S} 1$ ).

\section{Diversity of thermophilic endospores in deep water Gulf of Mexico surface sediments}

Investigating various incubation conditions on a subset of pasteurized EGoM sediments (see Supplementary Results for more details) revealed that the maximum number of 


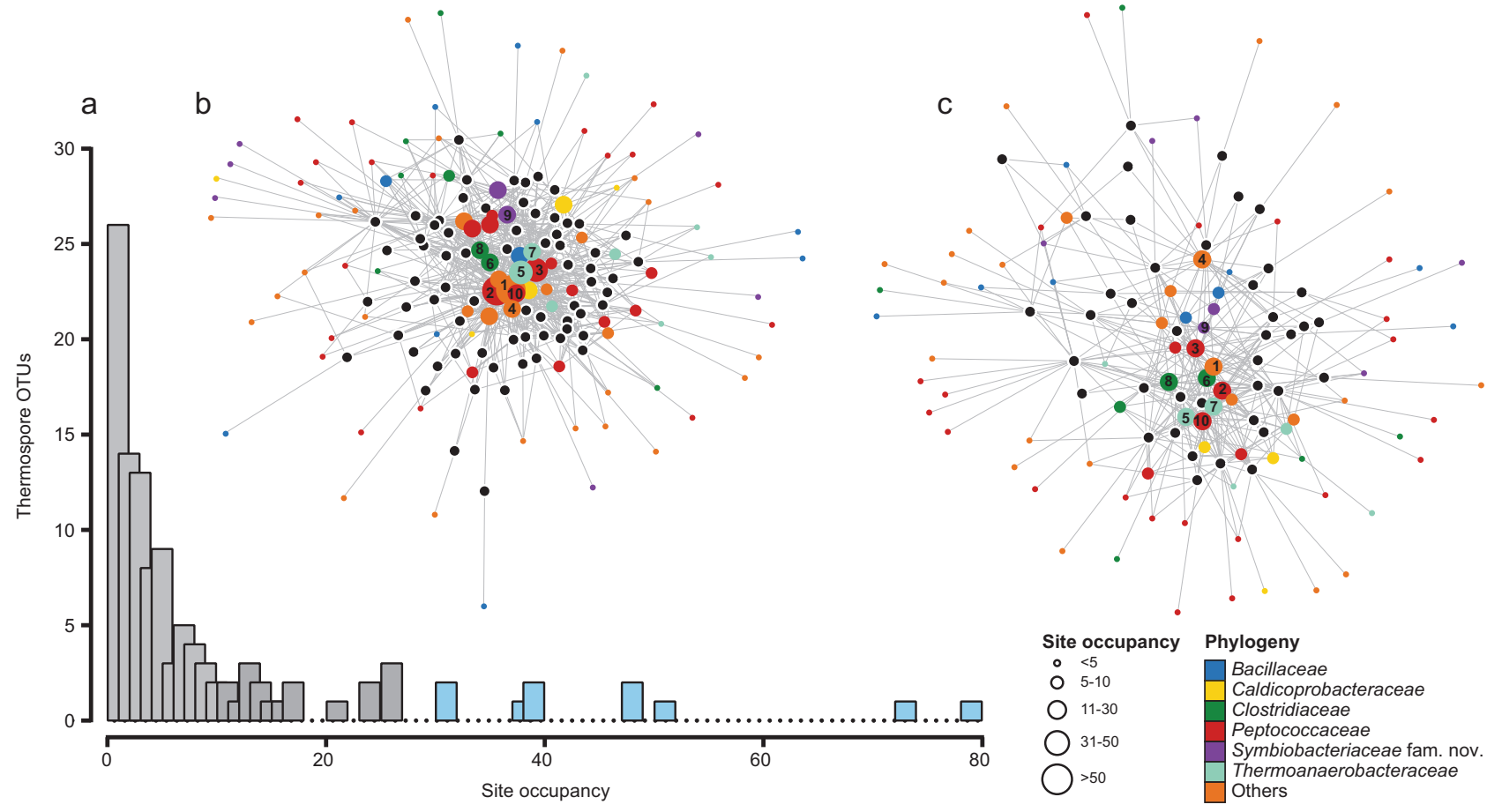

Fig. 3 a Histogram showing the site occupancy of the thermophilic endospore OTUs. The $X$ and $Y$ axes represent the number of locations at which each OTU was detected and the number of OTUs detected at that frequency, respectively. The light blue bars represent the top ten cosmopolitan OTUs found in $>30$ locations. b, c Bipartite network graphs of (b) oil-positive $(n=70)$ and (c) oil-negative $(n=40)$ sampling locations based on occurrence of thermophilic endospore OTUs. Colored nodes represent OTUs present in b oil-positive $(n=102$ OTUs) and coil-negative ( $n=85$ OTUs) locations. The colors of the OTU nodes indicate Family level taxonomy and the circle sizes

thermospores were detected in slurries amended with a mix of six organic acids after 14 days of incubation at $50{ }^{\circ} \mathrm{C}$ (Supplementary Figure S2) with comparable diversity within the Firmicutes observed among triplicate slurries (Supplementary Figure S3). Anoxic incubations in the above conditions of all 111 EGoM sediments generally resulted in reduced bacterial alpha diversity (Supplementary Table S2). Principal coordinate analysis of weighted UniFrac distances and non-metric multidimensional scaling analysis of Bray-Curtis distances both confirmed a shift in community structure in terms of phylogenetic composition of bacterial 16S rRNA genes and OTU counts, respectively, both before (0-day) and after (14-day) pasteurization and $50{ }^{\circ} \mathrm{C}$ incubation in most but not all samples (Supplementary Figure S4). Firmicutes was, as expected, the dominant phylum in almost all of the 14-day libraries $(n=110 / 111)$ representing $92 \%$ of total sequences and with relative abundances ranging from 35 to $99.9 \%$ across individual libraries. The fraction of total OTUs affiliated to Firmicutes increased from $3.2 \%(n=143 / 4490)$ in the rarefied 0 -day libraries to $32.5 \%(n=314 / 967)$. Subsequently, a total of 115 thermospore OTUs were identified across all high- indicate their site occupancy. Black nodes represent the sampling locations to which the gray lines connect the OTUs. The distance between the black location nodes reflects their thermospore OTU connectivity, e.g., locations sharing many OTUs are plotted close to each other in the inner periphery of the network whereas those that share few OTUs plot distantly to each other in the outer periphery. The top ten cosmopolitan OTUs are numbered on both networks and are plotted in the middle, while endemic and site-specific OTUs are plotted on the periphery

temperature incubations (Supplementary Table S3; Supplementary Figure S5). None of these OTUs were detected in any of the 0-day amplicon libraries (before pasteurization and incubation), consistent with these organisms being present in situ as endospores that germinated upon exposure to the high incubation temperature. Thermospore OTUs were detected in samples from all of the investigated locations except one (Fig. 1). Most of these OTUs were affiliated with the orders Clostridiales $(62.6 \%, n=72)$, Bacillales $(15.6 \%, n=18)$, and Thermoanaerobiales $(8.7 \%, n=10)$. The most represented families were Peptococcaceae (28.7\%, $n=33)$, Clostridiaceae $(10.4 \%, n=12)$, Bacillaceae $(11.3 \%$, $n=13$ ), and Thermoanaerobacteraceae $(7 \%, n=8)$ (Fig. 3; Supplementary Table 3 ). The number of detected thermospore OTUs per location ranged from 0 to 30 (on average, $9.8 \pm$ 5.9 (sd), $n=111$ ) (Supplementary Table S1). On average thermospore OTU richness was higher in Mississippi Canyon (14.7 \pm 8.2 per location) and Abyssal Plain (10.2 \pm 5.7 per location) sediments, compared to those in De Soto Valley $(8.8 \pm 4.6$ per location) and West Florida Shelf $(5.1 \pm 2$ per location) sediments, as depicted in Fig. 1. 
Distributions of thermophilic endospores in different geologic provinces of the Eastern Gulf of Mexico

The vast majority of the thermospore OTUs were either sitespecific (observed in only one location) or regionally endemic (restricted within a particular geologic province); e.g., 87 OTUs were found in ten or fewer locations and 26 of these were specific to a single location (16 in oil-positive and 10 in oil-negative locations) (Fig. 3a; Supplementary Table S3). Several of these OTUs have not been reported in previous studies of thermospores in cold marine sediments from around the world.

The top 10 most widely distributed or 'cosmopolitan' OTUs were all detected at more than 30 locations across different geologic provinces within the study area (Fig. 3a). Bipartite networks built from the OTU presence-absence matrix revealed that these OTUs occurred in both oilpositive and oil-negative locations (Fig. 3b, c). The more clustered appearance of the oil-positive locations around the cosmopolitan OTUs in the first network (Fig. 3b) compared to a relatively distributed appearance of the oil-negative locations in the second network (Fig. 3c) suggests that the cosmopolitan OTUs co-occur at a greater frequency in the oil-positive locations. The cosmopolitan thermospore OTUs were related to Caloranaerobacter (OTU8), Desulfotomaculum (OTU2, OTU3, OTU10), Gelria (OTU7), Moorella (OTU5), Sulfobacillus (OTU1), Symbiobacterium (OTU9), and Thermicanus (OTU4), and in one case was only assigned at the family level (Clostridiaceae-4: OTU6) due to a lack of close, cultivated relatives.

\section{Certain thermospores are associated with migration of thermogenic hydrocarbons}

To highlight thermospore OTUs strongly associated with oil-positive locations, the OTU presence-absence matrix was screened for thermospores that were present in at least five locations overall, with at least $80 \%$ of those locations being oil-positive. This approach revealed 12 OTUs within eight thermospore lineages that occurred predominantly in oil-positive locations. All 12 were distributed only within the deeper and more western geologic provinces, and not detected in sediments in the shallower West Florida Shelf (Fig. 4; Supplementary Figure S5). Assessment of OTU occurrence with TSF and UCM values using point biserial correlation highlighted four of these OTUs $(15,19,27$, and 34$)$ as having the strongest correlation $(p<0.05)$ with migrated hydrocarbons. As expected, these four OTUs were all found in locations with TSF and UCM values well above the average both for all oil-positive locations, and locations where the top 10 cosmopolitan OTUs were found (Fig. 5).
Most prominent among these was OTU15 $\left(r_{\mathrm{pb}-\mathrm{TSF}}=\right.$ $\left.0.39 ; r_{\mathrm{pb}-\mathrm{UCM}}=0.45 ; p<0.001\right)$, detected in 24 locations (average water depth $=2743 \mathrm{~m}$ ), 23 of which were oilpositive. This OTU can only be classified to the class level and BLAST searching using a representative sequence for this OTU showed fully identical top hits derived from only oil reservoirs and petroleum pipeline systems (data not shown). OTU19 $\left(r_{\mathrm{pb}-\mathrm{TSF}}=0.31 ; r_{\mathrm{pb}-\mathrm{UCM}}=0.27 ; p<0.001\right)$ belonging to the Caldicoprobacter clade, showed $100 \%$ site occupancy $(n=16$; average water depth $=2866 \mathrm{~m})$ in oilpositive sediments. Neither OTU15 nor OTU19 was confined to any given region within the EGoM study area, but most of their occurrences were in sediments in very deep water in the Abyssal Plain province (18 out of 24 for OTU15, and 14 out of 16 for OTU19).

Oil-associated OTU34 $\left(r_{\mathrm{pb}-\mathrm{TSF}}=0.21 ; r_{\mathrm{pb}-\mathrm{UCM}}=0.29 ; p\right.$ $<0.05$ ) along with four other OTUs were affiliated with the sulfate-reducing Desulfotomaculum lineage. The occurrence of two of these five OTUs (OTUs 34 and 36) was confined to the deep water Abyssal Plain province (Fig. 4; average water depths $=3124$ and $2961 \mathrm{~m}$, respectively). One of the closest cultured relatives ( $96 \%$ sequence identity) to these two deep water Desulfotomaculum thermospores is Desulfotomaculum geothermicum, a sulfate-reducing bacterium first isolated from the production well of a saline, geothermally active underground gas reservoir in the Paris Basin [57]. D. geothermicum strains have also been isolated from petroleum-bearing deep subsurface settings such as sandstone aquifers in Eastern Germany [58], fracture water from South African gold mines [59, 60], and offshore oil reservoirs [27]. Closest uncultured relatives of the other three OTUs inhabit hot subsurface gas fields [61, 62] and crude oil from high-temperature oil reservoirs [63].

The Desulfonispora clade contained another oilassociated OTU (OTU27; $r_{\mathrm{pb}-\mathrm{TSF}}=0.19 ; r_{\mathrm{pb}-\mathrm{UCM}}=0.28$; $p<0.05$ ), which remained confined within the deep water Abyssal Plain province along with OTU38, belonging to the Desulfitibacter clade. Both OTUs were close relatives to organisms found in a terrestrial mud volcano actively seeping petroleum hydrocarbons [64]. OTU50 and OTU53, belonging to Caldanaerocella and candidatus Desulforudis clades, respectively, were predominantly found in the Mississippi Canyon region. OTU41, belonging to the Hydrogenispora lineage, was detected in both deep and shallow sediments.

\section{Discussion}

Multiple warm habitats including geological features such as deep petroleum reservoirs and fractured ocean crust [19] have been proposed as the source environments that could supply dormant endospores of thermophilic bacteria to 
Fig. 4 An annotated 16S rRNAbased phylogenetic tree showing 12 thermophilic endospore OTUs which represent eight lineages (highlighted in eight different background colors) within the anaerobic

Clostridiales in the Phylum Firmicutes. Asterisks denote the four OTUs that are significantly correlated with migrated hydrocarbons. Two-colored pie charts indicate the percentage site occupancy for each of these OTUs in oil-positive and oilnegative ranked locations (cf. Fig. 2). Multi-colored stacked bars indicate site occupancies in different geologic provinces within the study area (none of these 12 OTUs were present in the West Florida Shelf province). The scale bar indicates $10 \%$ sequence divergence as inferred from PhyML. The black circles at the nodes of the branches indicate $>80 \%$ bootstrap support (100 resamplings). An extended tree showing the phylogeny and distribution of all 115 thermospore OTUs is presented in Supplementary Figure S5

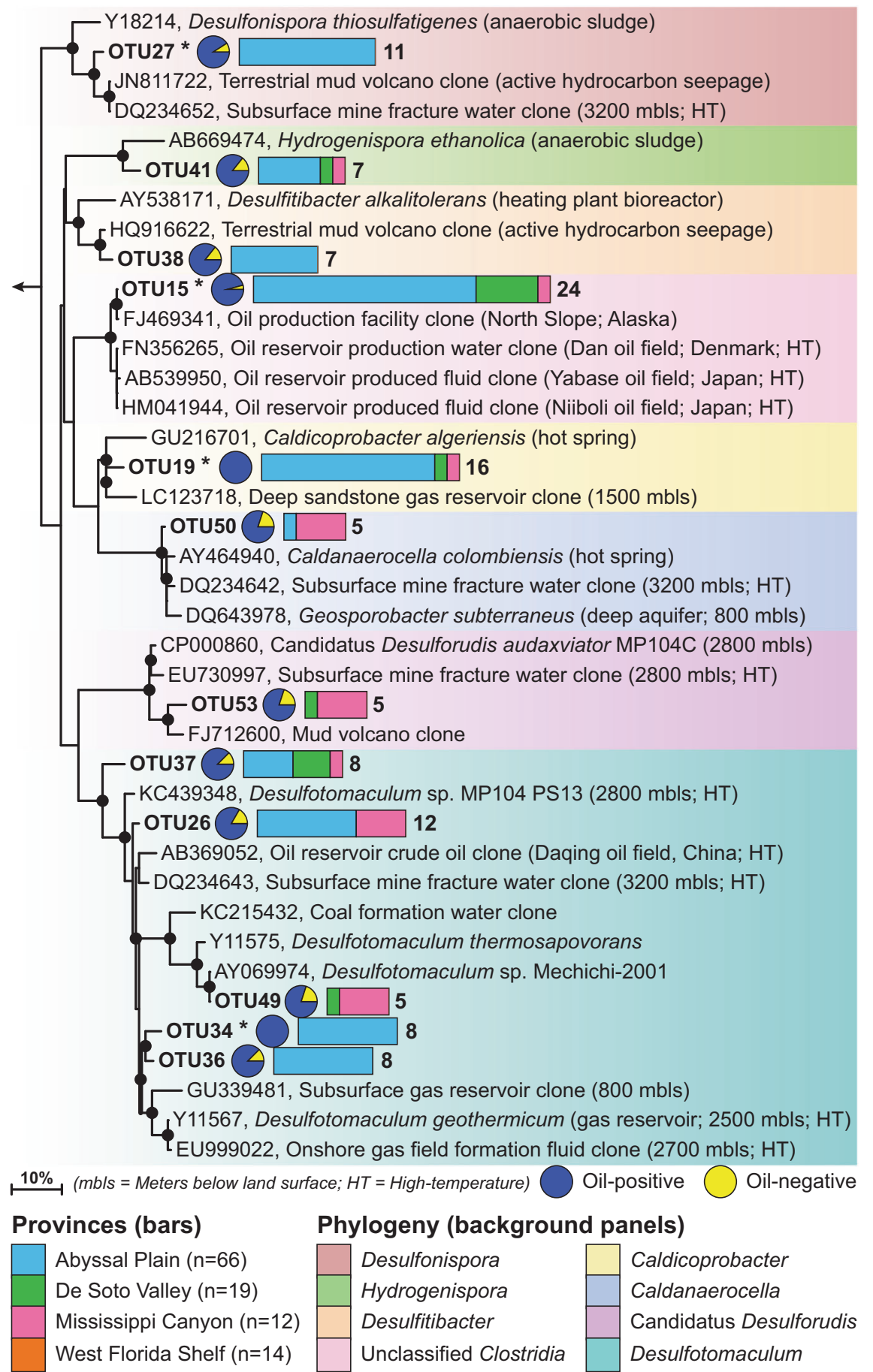

permanently cold marine sediments. Terrestrial habitats associated with industry, e.g., anaerobic digesters and wastewater treatment plants, have also been postulated as sources $[25,43]$. The large number of thermospore OTUs uncovered in this study $(>100)$ and previous biogeography surveys [20] suggest that multiple dispersal vectors originating from different warm environments could be responsible for the diversity of thermospores observed in the world's oceans. Focusing on petroleum-rich deep water
Gulf of Mexico sediments provides an opportunity to better constrain and assess subsurface petroleum reservoirs as habitats of origin for thermophilic spore-forming bacteria in the marine environment. The dispersal history in this scenario requires expulsion from subsurface oil reservoirs into the overlying water column via hydrocarbon seepage, followed by deposition via sedimentation into the seabed, where thermospores can be detected using the methods employed here. 
Fig. 5 Mean values of TSF maximum intensity (a) and the $\mathrm{UCM}$ in $\mu \mathrm{g} / \mathrm{g}$ dry sediment (b) for all oil-positive and oilnegative locations, for all locations where the top 10 cosmopolitan OTUs were observed (cf. Fig. 3), and for all locations where the 4 most strongly oil-associated OTUs were observed. Locations of the oil-associated OTUs are colored to match the respective OTU lineages indicated in the phylogenetic tree (cf. Fig. 4). Vertical dashed lines represent the threshold TSF intensity $(50,000)$ and UCM $(10 \mu \mathrm{g} / \mathrm{g}$ dry sediment) values used for classifying samples into oilpositive and oil-negative categories (cf. Fig. 2)

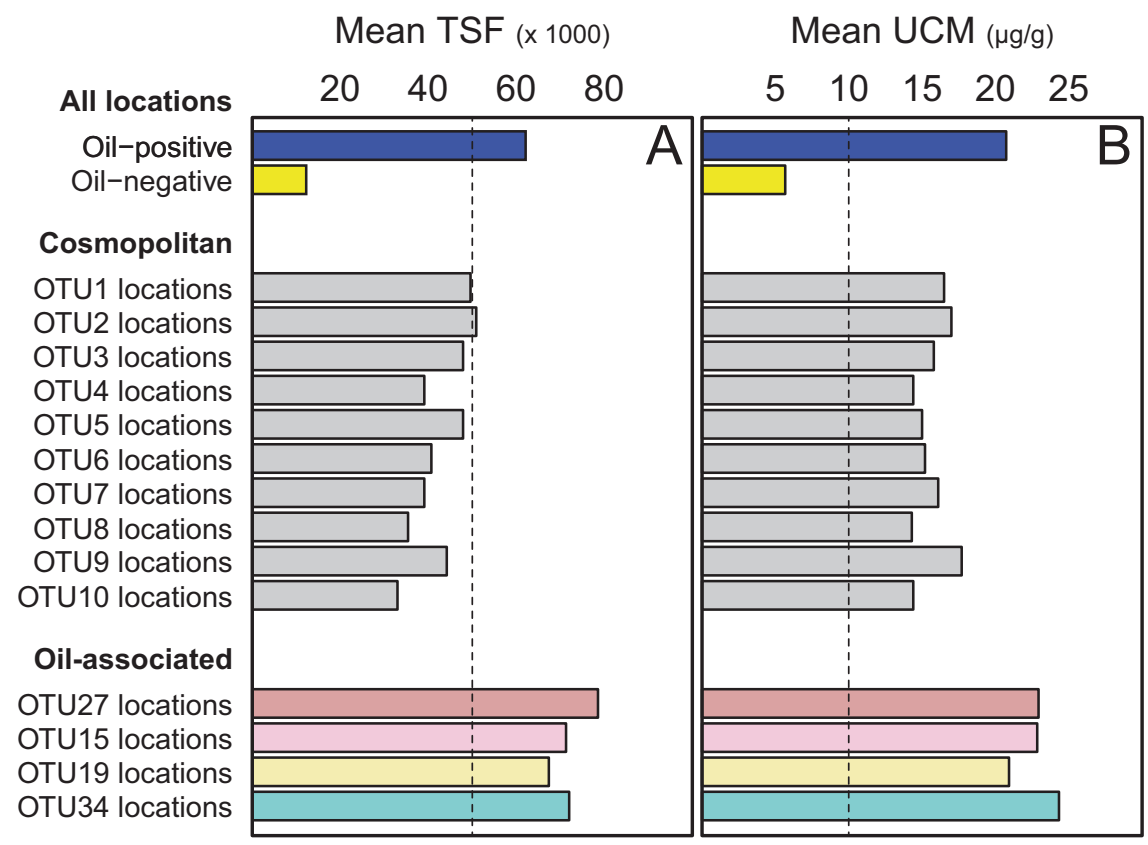

Restricted site occupancy demonstrated by a large proportion of the thermospore OTUs in our study (Fig. 3b, c) suggests a deterministic pattern of thermospore distribution within the EGoM area, and can be explained by local warm environments accompanied by dispersal limitation. Four novel thermospores with OTU occurrences significantly correlated with thermogenic hydrocarbons, and closest relatives from petroleum reservoirs, indicate that these four bacteria originated within petroleum-bearing subsurface sediments in the study area. For example, OTU15 showed the strongest correlation with migrated petroleum and its consensus sequence was identical (100\% 16S rRNA gene sequence identity; Fig. 4) to sequences of uncultured Clostridia reported from four high-temperature oil reservoirs (Alaska's North Slope, Dan in the Danish sector of the North Sea, and Yabase and Niiboli in Japan) around the world. This is the first time this lineage has been reported from a different environment other than a subsurface oil reservoir. The average depth and in situ temperatures of these oil fields range from 1100 to $2000 \mathrm{~m}$ and 40 to $80^{\circ} \mathrm{C}$ ([27, 65-67], respectively). Of the 24 EGoM sediments where OTU15 was detected, 23 had liquid hydrocarbons well above the overall average for the 111 sediments in our study (Fig. 5). Similarly OTU19 was found exclusively in sediments with oil values $(n=16)$ at levels well above the average (Fig. 5). Its closest relative, within the genus $\mathrm{Cal}$ dicoprobacter comes from a warm $\left(40-45^{\circ} \mathrm{C}\right)$ offshore petroleum reservoir ( $1500 \mathrm{~m}$ deep sandstone formation) harboring an indigenous microbial community dominated by Clostridiales [68].

The largest clade of thermospores (five OTUs including oil-associated OTU34) that were prevalent in the oil- positive locations belongs to the thermophilic Desulfotomaculum. Sulfate-reducing bacteria belonging to this genus have been isolated from oil reservoirs from around the world [69, 70]. Desulfotomaculum spp. are also well known inhabitants of other warm anoxic habitats, e.g., at mid-ocean ridges and in geothermally active aquifers [59]. In this regard, it should be noted that one of the most widely detected and cosmopolitan thermospore in these EGoM sediments (OTU2, found in 73 locations) also belongs to this genus. Thus, whereas Desulfotomaculum OTUs 26, 34, 36, 37, and 49 (Fig. 4) are most likely coming from EGoM oil reservoirs, the same cannot necessarily be concluded for the cosmopolitan D. geothermicum OTU2. Unlike the deep sea oil-associated thermospores, OTU2 was found in all four geologic provinces and in 18 out of the 40 oil-negative sediments (Fig. 3c). Either this particular Desulfotomaculum OTU is coming from a source environment that influences a larger area of the EGoM basin, or it is indeed also derived from subsurface petroleum reservoirs in our study area, but is more abundant or better equipped for widespread dispersal as has been shown for other closely related Desulfotomaculum spp. that produce extremely heatresistant endospores that seem very well suited for hot, harsh subsurface conditions [71].

The identification of only 12 OTUs as prime candidates for having experienced vertical emigration with oil implies that a large majority of the thermospores detected in this study (i.e., >100) may not originate in EGoM oil reservoirs and could have different dispersal histories. For example, the large variation in site occupancy among the 30 OTUs within the Desulfotomaculum lineage (Supplementary Figure S5) suggests that their distribution is likely influenced 
by a variety of dispersal vectors. Ocean currents have been argued to play a key role in passive dispersal of thermospores to distant locations from their point of origin [20]. Water mass circulation features in the semi-enclosed GoM basin are predominantly influenced by the Loop Current, a warm surface current [72] affecting this study area (Fig. 1; inset map). Passive dispersal of the more cosmopolitan OTUs from one geologic province to another, or more broadly, immigration into the EGoM from distant sources, e.g., the hydrocarbon seeps in the Caribbean Sea [30], via the Loop Current, may partly explain their widespread occurrence in the study area. Conversely, some of the locally restricted OTUs could also emigrate out of the EGoM through the Loop Current.

Multiple dispersal histories among the vast majority of thermospore OTUs underscore the uniqueness of the few OTUs that are likely dispersed via a deep-to-shallow mechanism. The 12 oil-associated Clostridia represent new candidate bioindicators for investigating hydrocarbon seepage as a dispersal vector connecting the deep and shallow biospheres. The reservoirs underneath the deep water basin of the Gulf of Mexico remain relatively underexplored compared to the well known working petroleum systems in its shallower north-western and north-central parts [73]. According to the geothermal gradient in the deep EGoM, this region is expected to contain interbedded sandstone and shale reservoirs with predicted formation temperatures ranging from 30 to $100^{\circ} \mathrm{C}$ [74] consistent with the physiology observed for the thermophilic bacteria discovered in this study, and inferred for their close relatives from other oil reservoirs around the world. These thermospores may therefore be useful for understanding deep oil reservoir microbiology and biogeochemistry in this region.

The oil reservoir microbiome examples highlighted above along with several others indicate that spore-forming Firmicutes are commonly found in these environments, especially deeper reservoirs with temperatures above $50{ }^{\circ} \mathrm{C}$ [40]. Besides these Clostridia, several other lineages of bacteria and archaea also inhabit oil reservoirs. Certain Thermotogae have only ever been found in oil reservoirs [75-77], an endemism suggesting that in principle they could also be cold sediment bioindicators for deeper reservoir environments if they are similarly ejected via hydrocarbon seeps and can in future also be detected at the seabed [13, 78, 79]. While it is not necessary that only spore-forming thermophiles would be subject to warm-to-cold upward transmigration, the results presented here reveal the ease with which thermospores can be studied as fingerprints of deep life and showcase petroleum geofluids as dispersal vectors connecting the deep and shallow biospheres.
Acknowledgements The authors thank Jody Sandel as well as the crew of RV GeoExplorer for collection of piston cores, onboard core processing, sample preservation, and shipment. Sienna Drake and Mohit Sethi assisted with the high-temperature incubation assays and Rhonda Clark provided valuable research support. We also wish to thank David Berry, Alexander Loy, Kasper Kjeldsen, Jeremy Fox, Xiaoli Dong, Jayne Rattray, Emil Ruff, and Marc Strous for valuable discussions and suggestions. Supportive collaborations with Andy Mort from the Geological Survey of Canada, and Richard Hatton from Geoscience Wales are also gratefully acknowledged. This work was financially supported by a Mitacs Elevate Postdoctoral Fellowship awarded to AC, and an ExxonMobil Knowledge Build Grant, a NSERC Strategic Project Grant, a Canada Foundation for Innovation (CFI) grant for instrumentation and a Campus Alberta Innovates Program (CAIP) Chair to CRJH.

\section{Compliance with ethical standards}

Conflict of interest The authors declare that they have no conflict of interest.

Open Access This article is licensed under a Creative Commons Attribution 4.0 International License, which permits use, sharing, adaptation, distribution and reproduction in any medium or format, as long as you give appropriate credit to the original author(s) and the source, provide a link to the Creative Commons license, and indicate if changes were made. The images or other third party material in this article are included in the article's Creative Commons license, unless indicated otherwise in a credit line to the material. If material is not included in the article's Creative Commons license and your intended use is not permitted by statutory regulation or exceeds the permitted use, you will need to obtain permission directly from the copyright holder. To view a copy of this license, visit http://creativecommons. org/licenses/by/4.0/.

\section{References}

1. Drake $\mathrm{H}$, Ivarsson $\mathrm{M}$, Bengston $\mathrm{S}$, Heim $\mathrm{C}$, Siljeström $\mathrm{S}$, Whitehouse MJ, et al. Anaerobic consortia of fungi and sulfate reducing bacteria in deep granite fractures. Nat Commun. 2017;8:55.

2. Edwards KJ, Becker K, Colwell F. The deep, dark energy biosphere: intraterrestrial life on Earth. Annu Rev Earth Planet Sci. 2012;40:551-68.

3. Kallmeyer J, Pockalny R, Adhikari RR, Smith DC, D'Hondt S. Global distribution of microbial abundance and biomass in subseafloor sediment. Proc Natl Acad Sci USA. 2012;109:16213-6.

4. Orsi WD, Edgcomb VP, Christman GD, Biddle JF. Gene expression in the deep biosphere. Nature. 2013;499:205-8.

5. Whitman WB, Coleman DC, Wiebe WJ. Prokaryotes: the unseen majority. Proc Natl Acad Sci USA. 1998;95:6578-83.

6. Hu P, Tom L, Singh A, Thomas BC, Baker BJ, Piceno YM et al. Genome-resolved metagenomic analysis reveals roles for candidate phyla and other microbial community members in biogeochemical transformations in oil reservoirs. mBio. 2016;7: e01669-15.

7. Vigneron A, Alsop EB, Lomans BP, Kyrpides NC, Head IM, Tsesmetzis N. Succession in the petroleum reservoir microbiome through an oil field production lifecycle. ISME J. 2017;11:2141-54.

8. Robador A, Jungbluth SP, LaRowe DE, Bowers RM, Rappé MS, Amend JP, et al. Activity and phylogenetic diversity of sulfatereducing microorganisms in low-temperature subsurface fluids within the upper oceanic crust. Front Microbiol. 2015;5:748. 
9. Topçuoğlu BD, Stewart LC, Morrison HG, Butterfield DA, Huber JA, Holden JF. Hydrogen limitation and syntrophic growth among natural assemblages of thermophilic methanogens at deep-sea hydrothermal vents. Front Microbiol. 2016;7:1240.

10. Schrenk MO, Huber JA, Edwards KJ. Microbial provinces in the subseafloor. Annu Rev Mar Sci. 2010;2:279-304.

11. Suess E. Marine cold seeps. In: Timmis KN, editor. Handbook of hydrocarbon and lipid microbiology. Berlin, Heidelberg: Springer Berlin Heidelberg; 2010; p. 185-203.

12. Gonnella T, Böhnke S, Inderbirken D, Garbe-Schönberg D, Seifert R, Mertens $\mathrm{C}$, et al. Endemic hydrothermal vent species identified in the open ocean seed bank. Nat Microbiol. 2016;1:16086.

13. Hoshino T, Toki T, Ijiri A, Morono Y, Machiyama H, Ashi J et al. Atribacteria from the subseafloor sedimentary biosphere disperse to the hydrosphere through submarine mud volcanoes. Front Microbiol. 2017;8:1135.

14. Locey KJ, Lennon JT. Scaling laws predict global microbial diversity. Proc Natl Acad Sci USA. 2016;113:5970-5.

15. Lynch MD, Neufeld JD. Ecology and exploration of the rare biosphere. Nat Rev Microbiol. 2015;13:217-29.

16. Pedrós-Alió C. The rare bacterial biosphere. Annu Rev Mar Sci. 2012;4:449-66.

17. Sogin ML, Morrison HG, Huber JA, Mark Welch D, Huse SM, Neal PR, et al. Microbial diversity in the deep sea and the underexplored "rare biosphere". Proc Natl Acad Sci USA. 2006;103:12115-20.

18. Lennon JT, Jones SE. Microbial seed banks: the ecological and evolutionary implications of dormancy. Nat Rev Microbiol. 2011;9:119-30.

19. Hubert C, Loy A, Nickel M, Arnosti C, Baranyi C, Brüchert V, et al. A constant flux of diverse thermophilic bacteria into the cold arctic seabed. Science. 2009;325:1541-4.

20. Müller AL, de Rezende JR, Hubert CRJ, Kjeldsen KU, Lagkouvardos I, Berry D, et al. Endospores of thermophilic bacteria as tracers of microbial dispersal by ocean currents. ISME J. 2014:8:1153-65.

21. Volpi M, Lomstein B, Sichert A, Røy H, Jørgensen B, Kjeldsen $\mathrm{K}$. Identity, abundance and reactivation kinetics of thermophilic fermentative endospores in cold marine sediment and seawater. Front Microbiol. 2017;8:131.

22. Bueche M, Wunderlin T, Roussel-Delif L, Junier T, Sauvain L, Jeanneret N, et al. Quantification of endospore-forming Firmicutes by quantitative PCR with the functional gene spo0A. Appl Environ Microbiol. 2013;79:5302-12.

23. Wunderlin T, Junier T, Roussel-Delif L, Jeanneret N, Junier P. Endospore-enriched sequencing approach reveals unprecedented diversity of Firmicutes in sediments. Environ Microbiol Rep. 2014;6:631-9.

24. Hubert C, Arnosti C, Brüchert V, Loy A, Vandieken V, Jørgensen BB. Thermophilic anaerobes in Arctic marine sediments induced to mineralize complex organic matter at high temperature. Environ Microbiol. 2010;12:1089-104.

25. de Rezende JR, Kjeldsen KU, Hubert CRJ, Finster K, Loy A, Jørgensen BB. Dispersal of thermophilic Desulfotomaculum endospores into Baltic Sea sediments over thousands of years. ISME J. 2013;7:72-84.

26. Dahle H, Garshol F, Madsen M, Birkeland NK. Microbial community structure analysis of produced water from a hightemperature North Sea oil-field. Antonie Van Leeuwenhoek. 2008;93:37-49.

27. Gittel A, Sorensen KB, Skovhus TL, Ingvorsen K, Schramm A. Prokaryotic community structure and sulfate reducer activity in water from high-temperature oil reservoirs with and without nitrate treatment. Appl Environ Microbiol. 2009;75:7086-96.
28. Kaster KM, Bonaunet K, Berland H, Kjeilen-Eilertsen G, Brakstad OG. Characterisation of culture-independent and -dependent microbial communities in a high-temperature offshore chalk petroleum reservoir. Antonie Van Leeuwenhoek. 2009;96:423-39.

29. Hubert C, Judd A. Using microorganisms as prospecting agents in oil and gas exploration. In: Timmis KN, editor. Handbook of hydrocarbon and lipid microbiology. Berlin, Heidelberg: Springer; 2010; p. 2711-25.

30. Cordes EE, Bergquist DC, Fisher CR. Macro-ecology of Gulf of Mexico cold seeps. Annu Rev Mar Sci. 2009;1:143-68.

31. Ruff SE, Biddle JF, Teske AP, Knittel K, Boetius A, Ramette A. Global dispersion and local diversification of the methane seep microbiome. Proc Natl Acad Sci USA. 2015;112:4015-20.

32. MacDonald IR, Reilly Jr JF, Best SE, Venkataramaiah R, Sassen $\mathrm{R}$, Guinasso NL et al. Remote sensing inventory of active oil seeps and chemosynthetic communities in the Northern Gulf of Mexico. In: Schumacher D, Abrams MA, editors. Hydrocarbon migration and its near-surface expression: AAPG memoir 66. Tulsa, Oklahoma, USA: The American Association of Petroleum Geologists; 1996. p. 27-37.

33. MacDonald IR, Bohrmann G, Escobar E, Abegg F, Blanchon P, Blinova V, et al. Asphalt volcanism and chemosynthetic life in the Campeche Knolls, Gulf of Mexico. Science. 2004;304:999.

34. Bernard BB, Brooks JM, Sackett WM. Natural gas seepage in the Gulf of Mexico. Earth Planet Sci Lett. 1976;31:48-54.

35. Orcutt BN, Joye SB, Kleindienst S, Knittel K, Ramette A, Reitz $A$, et al. Impact of natural oil and higher hydrocarbons on microbial diversity, distribution, and activity in Gulf of Mexico cold-seep sediments. Deep Sea Res 2 Top Stud Oceanogr. 2010;57:2008-21.

36. Pop Ristova P, Wenzhofer F, Ramette A, Felden J, Boetius A. Spatial scales of bacterial community diversity at cold seeps (Eastern Mediterranean Sea). ISME J. 2015;9:1306-18.

37. Kleindienst S, Ramette A, Amann R, Knittel K. Distribution and in situ abundance of sulfate-reducing bacteria in diverse marine hydrocarbon seep sediments. Environ Microbiol. 2012;14:2689-710.

38. Kleindienst S, Herbst FA, Stagars M, von Netzer F, von Bergen M, Seifert J, et al. Diverse sulfate-reducing bacteria of the Desulfosarcina/Desulfococcus clade are the key alkane degraders at marine seeps. ISME J. 2014;8:2029-44.

39. Shelton JL, Akob DM, McIntosh JC, Fierer N, Spear JR, Warwick $\mathrm{PD}$ et al. Environmental drivers of differences in microbial community structure in crude oil reservoirs across a methanogenic gradient. Front Microbiol. 2016;7:1535.

40. Hubert CRJ, Oldenburg TB, Fustic M, Gray ND, Larter SR, Penn $\mathrm{K}$, et al. Massive dominance of Epsilonproteobacteria in formation waters from a Canadian oil sands reservoir containing severely biodegraded oil. Environ Microbiol. 2012;14:387-404.

41. Bernard B, Brooks J, Baillie P, Decker J, Teas P, Orange D. Surface geochemical exploration and heat flow surveys in fifteen (15) frontier Indonesian basins. Proceedings, Indonesia Petroleum Association, Thirty-Second Annual Convention \& Exhibition, 2008.

42. Goñi MA, Ruttenberg KC, Eglinton TI. Sources and contribution of terrigenous organic carbon to surface sediments in the Gulf of Mexico. Nature 1997;389:275.

43. Isaksen MF, Bak F, Jørgensen BB. Thermophilic sulfate-reducing bacteria in cold marine sediment. FEMS Microbiol Ecol. 1994;14:1-8.

44. Klindworth A, Pruesse E, Schweer T, Peplies J, Quast C, Horn M, et al. Evaluation of general $16 \mathrm{~S}$ ribosomal RNA gene PCR primers for classical and next-generation sequencing-based diversity studies. Nucleic Acids Res. 2013;41:e1.

45. Dong X, Kleiner M, Sharp CE, Thorson E, Li C, Liu D et al. Fast and simple analysis of MiSeq amplicon sequencing data with MetaAmp. Front Microbiol. 2016; 8:1461. 
46. McMurdie PJ, Holmes S. phyloseq: an R package for reproducible interactive analysis and graphics of microbiome census data. PLoS ONE. 2013;8:e61217.

47. Abecasis AB, Serrano M, Alves R, Quintais L, Pereira-Leal JB, Henriques AO. A genomic signature and the identification of new sporulation genes. J Bacteriol. 2013;195:2101-15.

48. Nelson MC, Morrison HG, Benjamino J, Grim SL, Graf J. Analysis, optimization and verification of Illumina-generated $16 \mathrm{~S}$ rRNA gene amplicon surveys. PLoS ONE. 2014;9:e94249.

49. Csárdi G, Nepusz T. The igraph software package for complex network research. InterJournal. 2006;Complex Systems: 1695.

50. Emad A, Bailey P. wCorr: weighted correlations. R package version 1.9.1, 2017. https://CRAN.R-project.org/package=wCorr

51. Pruesse E, Peplies J, Glockner FO. SINA: accurate highthroughput multiple sequence alignment of ribosomal RNA genes. Bioinformatics. 2012;28:1823-9.

52. Quast C, Pruesse E, Yilmaz P, Gerken J, Schweer T, Yarza P, et al. The SILVA ribosomal RNA gene database project: improved data processing and web-based tools. Nucleic Acids Res. 2013;41:D590-6.

53. Ludwig W, Strunk O, Westram R, Richter L, Meier H, Yadhukumar, et al. ARB: a software environment for sequence data. Nucleic Acids Res. 2004;32:1363-71.

54. Letunic I, Bork P. Interactive tree of life (iTOL)v3: an online tool for the display and annotation of phylogenetic and other trees. Nucleic Acids Res. 2016;44:W242-5.

55. Abrams MA. Significance of hydrocarbon seepage relative to petroleum generation and entrapment. Mar Pet Geol. 2005;22:457-77.

56. Wenger LM, Isaksen GH. Control of hydrocarbon seepage intensity on level of biodegradation in sea bottom sediments. Org Geochem. 2002;33:1277-92.

57. Daumas S, Cord-Ruwisch R, Garcia JL. Desulfotomaculum geothermicum sp. nov., a thermophilic, fatty acid-degrading, sulfatereducing bacterium isolated with $\mathrm{H}_{2}$ from geothermal ground water. Antonie Van Leeuwenhoek. 1988;54:165-78.

58. Sass H, Cypionka H. Isolation of sulfate-reducing bacteria from the terrestrial deep subsurface and description of Desulfovibrio cavernae sp. nov. Syst Appl Microbiol. 2004;27:541-8.

59. Aüllo T, Ranchou-Peyruse A, Ollivier B, Magot M. Desulfotomaculum spp. and related gram-positive sulfate-reducing bacteria in deep subsurface environments. Front Microbiol. 2013;4:362.

60. Onstott TC, Magnabosco C, Aubrey AD, Burton AS, Dworkin JP, Elsila JE, et al. Does aspartic acid racemization constrain the depth limit of the subsurface biosphere? Geobiology. 2014;12:1-19.

61. Ehinger S, Seifert J, Kassahun A, Schmalz L, Hoth N, Schlömann M. Predominance of Methanolobus spp. and Methanoculleus spp. in the Archaeal communities of saline gas field formation fluids. Geomicrobiol J. 2009;26:326-38.

62. Berlendis S, Lascourreges JF, Schraauwers B, Sivadon P, Magot M. Anaerobic biodegradation of BTEX by original bacterial communities from an underground gas storage aquifer. Environ Sci Technol. 2010;44:3621-8.

63. Yamane $\mathrm{K}$, Maki $\mathrm{H}$, Nakayama $\mathrm{T}$, Nakajima $\mathrm{T}$, Nomura $\mathrm{N}$, Uchiyama $\mathrm{H}$, et al. Diversity and similarity of microbial communities in petroleum crude oils produced in Asia. Biosci Biotechnol Biochem. 2008;72:2831-9.

64. Chang YH, Cheng TW, Lai WJ, Tsai WY, Sun CH, Lin LH, et al. Microbial methane cycling in a terrestrial mud volcano in eastern Taiwan. Environ Microbiol. 2012;14:895-908.
65. Duncan KE, Gieg LM, Parisi VA, Tanner RS, Tringe SG, Bristow $\mathrm{J}$, et al. Biocorrosive thermophilic microbial communities in Alaskan North Slope oil facilities. Environ Sci Technol. 2009;43:7977-84.

66. Kobayashi H, Endo K, Sakata S, Mayumi D, Kawaguchi H, Ikarashi $\mathrm{M}$, et al. Phylogenetic diversity of microbial communities associated with the crude-oil, large-insoluble-particle and formation-water components of the reservoir fluid from a nonflooded high-temperature petroleum reservoir. J Biosci Bioeng. 2012;113:204-10.

67. Mayumi D, Mochimaru H, Yoshioka H, Sakata S, Maeda H, Miyagawa $\mathrm{Y}$, et al. Evidence for syntrophic acetate oxidation coupled to hydrogenotrophic methanogenesis in the hightemperature petroleum reservoir of Yabase oil field (Japan). Environ Microbiol. 2011;13:1995-2006.

68. Kimura H, Nashimoto H, Shimizu M, Hattori S, Yamada K, Koba $\mathrm{K}$, et al. Microbial methane production in deep aquifer associated with the accretionary prism in Southwest Japan. ISME J. 2010;4:531-41.

69. Nilsen RK, Torsvik T, Lien T. Desulfotomaculum thermocisternum sp. nov., a sulfate reducer isolated from a hot North Sea oil reservoir. Int J Syst Evol Microbiol. 1996;46:397-402.

70. Tardy-Jacquenod C, Magot M, Patel BKC, Matheron R, Caumette P. Desulfotomaculum halophilum sp. nov., a halophilic sulfatereducing bacterium isolated from oil production facilities. Int $\mathbf{J}$ Syst Evol Microbiol. 1998;48:333-8.

71. O'Sullivan LA, Roussel EG, Weightman AJ, Webster G, Hubert CRJ, Bell E, et al. Survival of Desulfotomaculum spores from estuarine sediments after serial autoclaving and high-temperature exposure. ISME J. 2015;9:922-33.

72. Ohlmann JC, Niiler PP. Circulation over the continental shelf in the northern Gulf of Mexico. Prog Oceanogr. 2005;64:45-81.

73. Weimer P, Bouroullec R, Adson J, Cossey SPJ. An overview of the petroleum systems of the northern deep-water Gulf of Mexico. Am Assoc Pet Geol Bull. 2017;101:941.

74. Ehrenberg SN, Nadeau PH, Steen $\varnothing$. A megascale view of reservoir quality in producing sandstones from the offshore Gulf of Mexico. Am Assoc Pet Geol Bull. 2008;92:145.

75. Nesbø CL, S Swithers K, Dahle H, Haverkamp TH, Birkeland N$\mathrm{K}$, Sokolova $\mathrm{T}$, et al. Evidence for extensive gene flow and Thermotoga subpopulations in subsurface and marine environments. ISME J. 2015;9:1532.

76. Ollivier B, Alazard D. The oil reservoir ecosystem. In: Timmis $\mathrm{KN}$, editor. Handbook of hydrocarbon and lipid microbiology. Berlin, Heidelberg: Springer; 2010. p. 2259-69.

77. Cappelletti M, Zannoni D, Postec A, Ollivier B. Members of the order Thermotogales: from microbiology to hydrogen production. In: Zannoni D, De Philippis R, editors. Microbial bioenergy: hydrogen production. Netherlands, Dordrecht: Springer; 2014. p. 197-224.

78. Nielsen SD, Volpi M, Löbmann K, Kjeldsen KU, Røy H. Quantification of anaerobic thermophilic endospores in marine sediment by microcalorimetry, and its use in bioprospecting for gas and oil. Limnol Oceanogr Methods. 2017;15:519-30.

79. Niemann H, Elvert M, Hovland M, Orcutt B, Judd A, Suck I, et al. Methane emission and consumption at a North Sea gas seep (Tommeliten area). Biogeosciences. 2005;2:335-51. 